Article

\title{
Hesitant Fuzzy Sets Based Symmetrical Model of Decision-Making for Estimating the Durability of Web Application
}

\author{
Kavita Sahu ${ }^{1}$, Fahad A. Alzahrani ${ }^{2}{ }^{\circledR}$, R. K. Srivastava ${ }^{1}$ and Rajeev Kumar ${ }^{3,4, *}$ \\ 1 Department of Computer Science, Dr. Shakuntala Misra National Rehabilitation University, \\ Lucknow 226017, Uttar Pradesh, India; kavi9839@gmail.com (K.S.); rks100664@gmail.com (R.K.S.) \\ 2 Computer Engineering Department, College of Computer and Information Systems, \\ Umm Al-Qura University, Makkah 21955, Saudi Arabia; fayzahrani@uqu.edu.sa \\ 3 Department of Information Technology, Babasaheb Bhimrao Ambedkar University, \\ Lucknow 226025, Uttar Pradesh, India \\ 4 Department of Computer Application, Shri Ramswaroop Memorial University, Lucknow-Deva Road, \\ Barabanki 225003, Uttar Pradesh, India \\ * Correspondence: rajeevkr.rs@bbau.ac.in or rs0414@gmail.com
}

Received: 24 September 2020; Accepted: 21 October 2020; Published: 26 October 2020

\begin{abstract}
The development of web applications essentially relies on users' demands who expect highly efficacious but cost effective software services. Managing time and cost so as to develop web applications that cater to the users' need is a challenge for developers at present. Moreover, low-cost maintenance can only be achieved by enhancing the durability of the web applications. Identifying characteristics of durability is a complex task because the different experts have different opinions regarding the significance of characteristics that determine durability quotient of the web applications. As established by the best practices undertaken in this context, some experts consider quality to be the most important factor for determining durability. Therefore, the present study enlists multi-criteria decision-based symmetrical technique to address the multi-vector option availability for the apt selection of the characteristics for durability. Furthermore, it has also been identified that a numerical assessment of web applications' durability can affect the service life and low-cost management in web applications. In this context, to achieve high durability and longevity in web applications, this paper attempts to illustrate and perform a numerical evaluation of durability characteristics. By understanding the various characteristics and their significance towards durability, the paper finds that the hesitant fuzzy-based symmetrical technique of the Analytic Hierarchy Process (AHP) and Technique for Order of Preference by Similarity to Ideal Solution (TOPSIS) is an effective methodology for evaluating web applications' durability. For evaluating the quality of the results and establishing their sensitivity, the authors have assessed the outcomes on six different projects of the University. Additionally, results assessed and discussed in this paper would be a conclusive reference for the developers in their attempts to develop highly durable and manageable web applications.
\end{abstract}

Keywords: web application durability; symmetrical development process; hesitant fuzzy sets; AHP; TOPSIS

\section{Introduction}

The exponential increase in the use of web applications can be witnessed in almost every field today. However, the ubiquitous use of web applications has also jeopardized the security of users' information. Constant threats of cyber assaults and instances of data theft have become a major concern for the web application developers and the security practitioners. Nowadays, it is easy to 
build and use the web application, but difficult to maintain its security [1]. Step-by-step evolution of web application is a time consuming process that demands high cost and complex architecture. Hence, web application designers need to produce highly effective as well as durable web applications. Durability of the web applications is now deemed as the foremost priority and has become a major challenge for the developers.

The present day designers are focusing more on the meticulous evaluation of reliability ( $a$ sub-factor of durability) so as to strengthen the durability quotient of the web applications [1,2]. Producing durable web applications is not a one-day concept; it is a long term procedure that involves design phase characteristics to application-level abilities. A critical survey for software management, done in this league, cites that $73 \%$ of the companies are updating their digital infrastructures by 2020 [2]. Cisco's Global Cloud Index has also discussed this issue with specific reference to the time period from 2013 to 2018 [3]. The survey states that the methodology of Software as a Service (SaaS) is going to provide and apply cloud-based work procedures by the next 5 years. Furthermore, the survey tells that revising and upgrading the life span of web applications has become the core focus of the organizations in 2020 [4]. Hence, it is evident that the users are demanding durable as well as efficient web applications. Web application's durability as a concept for development was first introduced in 2013 [5]. As propositioned in the stated study, durability of web applications is a path to achieve and provide long-lasting as well as user centric web applications in service. Hence, web application's life is a crucial element in web application development and after deployment also.

R. Kumar's study on the concept of durability suggests that the durability of web applications has some significant characteristics or characteristics like trustworthiness, dependability, human-trust, and usability [6]. But integrating web application and durability concept in one plot gives an additional service life to web applications. In the context of the proposed study, the authors have undertaken a quantitative assessment of durability of web applications based on the characteristics that determine durability. It is also proved that quality and durability characteristics effectively contribute to implementing a web application durability assessment [7]. However, evaluation, which is compiled by using more than one decisions makers is more effective; therefore, the durability of a web application can be more effectively achieved through the Multiple Criteria Decision Making (MCDM) methodology $[8,9]$.

There are several MCDM approaches for solving decision-related problems [9]. For the proposed article, the authors have applied the Hesitant fuzzy-based Analytic Hierarchy Process (AHP) and Technique for Order of Preference by Similarity to Ideal Solution (TOPSIS) $[7,8]$. Both AHP and TOPSIS are popular MCDM approaches for finding precise solutions among various alternatives and attributes. The nature of attributes involved in estimation of durability of web application requires a hierarchy based MCDM method, which is AHP. Furthermore for determining the best alternative among several others, TOPSIS proves to be a good MCDM method. Various researchers have used this hybrid approach for decision making related problems $[9,10]$. However, AHP is the most widely adopted and deployed MCDM technique and is known to produce more accurate results [11]. The hierarchy model for estimation is applied in AHP, and the networked model is applied in Analytic Network Process (ANP) for estimation in decision making. Moreover, both techniques acquire pair-wise comparison matrix data and rank the alternatives for result testing. AHP gives the complimentary advantage through which every attribute of the discussed hierarchy is independent in itself and the same is applied in alternatives. On the contrary, as is evident in real time scenarios, the characteristics and alternatives are mutually dependent on each other [12].

The MCDM technique of hesitant fuzzy AHP-TOPSIS was adopted by Bijoyeta Roy et al. for web application project selection [13]. This technique helped in selecting the best available options, priority-wise, from the host of project decisions and alternative ranks. Madjit Tavana et al. also adopted hesitant fuzzy AHP-TOPSIS for estimating a single characteristic such as community for the willingness of e-governance [14]. Baozhu Li et al. estimated the computer security characteristics by the hesitant fuzzy AHP technique [15]. Thus, a perusal of previous literature studies in this context establishes the 
accuracy of the hesitant fuzzy-based symmetrical AHP-TOPSIS technique for critical criteria estimation. To obtain a more conclusive analysis in our study, we have also undertaken the estimation of durability characteristics by employing hesitant fuzzy AHP-TOPSIS. The main impacts of this research work are as:

- Estimate web application durability that will deliver rules and strategies for development of durable web application.

- Hesitant fuzzy sets based AHP-TOPSIS technique is adopted to evaluate the durability of web application. Hesitant fuzzy sets based AHP technique and hesitant fuzzy sets based TOPSIS technique are well known and popular during solving multi-criteria decision making related problems and provide precise and efficient results.

- The set of characteristics of durability used in this research work to assess durability of web application through unified approach of hesitant fuzzy based AHP and TOPSIS is unique.

- Six different versions of an institutional web application are taken as alternatives to evaluate the real time impact and validate the results.

- This study's empirical initiative aims at providing insights about determining how formal and well-proven durability characteristics are followed throughout the development life cycle of web application.

The rest of the work is divided into the following segments: Section 2 discusses Materials and Methods and includes durability characteristics of web application and hesitant fuzzy sets based AHP-TOPSIS methodology; Section 3 provides numerical analysis and results, sensitivity analysis, and contains comparison through different methods; and Section 4 gives the conclusion of this research work.

\section{Materials and Methods}

\subsection{Durability of Web Application}

Durability of the web application improves the quality of web applications effectively [16]. In fact, the quality of web application has always been dependent on its durability, i.e., a durable web application is considered to be a highly effective and useful web application. However, achieving the best quality standards and ensuring optimum durability of the web application is not a one step process and requires periodic initiatives. Managing durability is a task of maintaining reusability of web application from time to time [17].

The service life for a software or web application is always a key characteristic of its functionality and quality. Despite this, as observed by experts, durability is still not the core concern during the development phases of the web applications as the focus is on optimizing the usability of the web applications. This creates a gap between durability and functionality of the web applications, and further decreases the service life of the web applications. Every customer needs a web application with long service life, and a gap in durability factor in development shelves the longevity of the web applications [5,6]. Moreover, the service life of any web application directly portrays the durability of its design and architecture.

The concept of relating maintenance and durability has been discussed by Khan et al. [8]. According to Cusick, serviceability of a web application is related to its durability, and the serviceability of web application can be enhanced further if the durability has been achieved to the desired level [18]. Durable web application is defined as user's satisfaction and their demands fulfillment as well as its longevity during its use [5,7]. Thus, it is evident that instead of a normal web application, a durable web application is not only effective but also an attractive investment for the users. A web application's durability is connected to longevity, and the web application's progress is involved with its durability directly or indirectly and vice-versa. 
Assuring web application's durability requires a judicious selection of the attributes that determine durability. Some characteristics of durability have the ability and potential to effectively maintain and manage the web application. Many researchers believe that longevity is the same as durability in web application design [4-9]. Durability is an integral feature in security, defense, educational, and banking sector web applications. There are various characteristics and sub-characteristics of durability that significantly affect the quality of web application. We have identified these characteristics through a literature review of almost seven research papers $[6-9,18-20]$. These researches indicate that the chosen characteristics affect the durability of any software and web application, directly or indirectly $[6-9,20]$. Some of the key characteristics in this context are: Dependability $[5,6]$, trustworthiness [6,7], human trust [5,7], usability [6,8], confidentiality [5,8], consumer integrity $[8,9]$, reliability [5,9], maintainability [18], accountability [18,19], survivability [8,20], availability [18], accessibility [19], and user satisfaction [20]. The relationship between these characteristics has been shown in Figure 1.

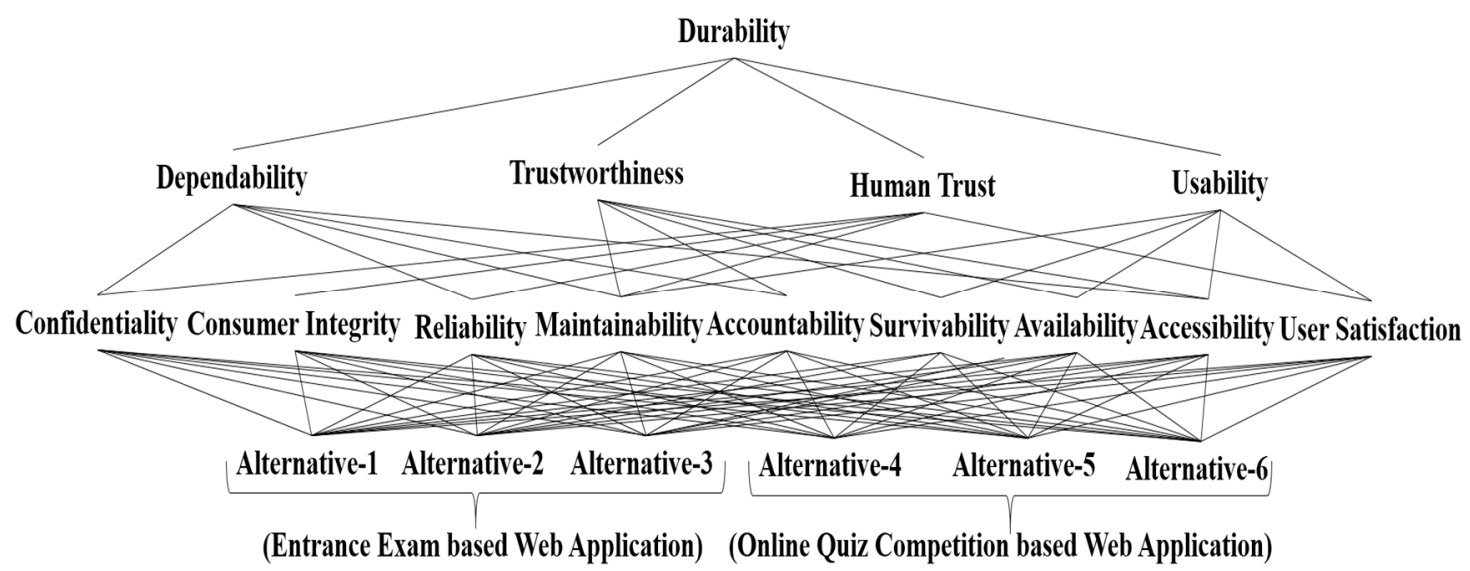

Figure 1. Durability characteristics of web application.

Figure 1 shows that the quality of the web application can be enhanced by applying the durability factor in the development phase. In Figure 1, six alternatives have been taken for choosing the best alternative between two web applications. The two alternatives are real time web applications. One of these is the entrance exam based web application, and the second one is an online quiz competition based web application. Three different alternatives for both the web applications have been taken into this research for estimation of durability of web application.

Furthermore, in order to enhance the durability of a web application, it is important to identify and estimate the various sub-characteristics or characteristics of durability by an effective computational methodology. Assessment of durability factors include numerical categorization and evaluation of various quality characteristics that contribute towards web application's service life. Characteristics of web application durability are defined as:

- Dependability: The system is said to be dependable if a computer works as expected and the user is confident at the same time about its working. Describing the significance of this factor in durability is an effective way to construct web application. A web application's durability factor is also inherited by dependability. It inherits the service life and working process of web application. On the other hand, by underlining the definition of dependability factor, it is clearly illustrated that the software service life span is important for user's expectations. Hence, in these terms, the web application's durability will be stronger with the help of dependable software. There are many dependability characteristics but web application durability affects only a few of them which are mentioned in Figure 1.

- Trustworthiness: According to the defining terms of this factor, if web application can prevent, tackle and survive the condition of attacks, failure, and other harmful situations, then it will 
possess trustworthiness. Trustworthiness ensures that the software will perform as expected. There are many trustworthiness characteristics but web application durability affects only a few of them which are mentioned in Figure 1.

- Human Trust: Trust in human to human operations is one of the most significant characteristics for long serviceability in web applications. In web application terms, human trust is identified as the consumer's trust in the developer. The characteristics that strengthen each other are web application durability and human trust. There are many human trust characteristics but web application durability affects only a few of them which are mentioned in Figure 1.

- Usability: If a web application interface is simple or easy to use, then it automatically means that is usable. Accessibility, availability, survivability, maintainability, and ultimately satisfaction are the five main enhancements that make for a usable web application, as per the end-users' experience. Further, the characteristics that strengthen each other are web application durability and usability. There are many usability characteristics but web application durability affects only a few of them which are mentioned in Figure 1.

The tree of web application that has been shown in Figure 1 is further classified into two levels. One or more characteristics of the higher level are affected by the characteristics at another level. However, the effect of the characteristics is not always same for every level. For instance, dependability, human trust, and trustworthiness are impacted by reliability but the impact is not the same for all of them. The impacts of the same characteristics are differentiated with the help of a tree of characteristics among the other characteristics at a higher level. For achieving the longevity of the web applications during the development process, the practitioners need to understand and assess the web application's durability. Web application durability is affected by the nine characteristics at level 2 which are defined below:

- Confidentiality: It is an ability to manage and provide data only to the authorized users.

- Consumer Integrity: Integrity is an ability of application that prevents and manages the originality of information within the web application.

- Reliability: It is an ability that shows the performance consistency of application in a controlled condition for a specified time period.

- Maintainability: Is the ability that defines rearrangements and patching in web applications for a specified course of work.

- Accountability: Accountability assures the role and amenableness of every node or entity of users in web application.

- Survivability: Is the ability of web application to fulfill its desired objective, whether it is in an attack situation or failure.

- Availability: It assures the presence of information $24 \times 7$ in a web application for its authorized users.

- Accessibility: Is the ability of web applications to control user information rights within the web application environment.

- User Satisfaction: It assures customer satisfaction and demands in a web application by timely upgradation.

In a nutshell, these characteristics play a vital role in estimating web application's durability, hence weightage of these characteristics in estimation of durability need to be known. Although it is a very critical process to identify, prioritize, and estimate characteristics, without it, the practitioners cannot achieve the target of a profitable and successful web application product. Moreover, web application durability plays a vital role in the optimization of maintenance issues. Essentially, understanding durability of web application is an ambiguous process due to its vast characteristics and area. Hence, experts' opinions need to be collated for deciding on the most conversant attributes. Different experts might have varying views and to mitigate the uncertainties caused by multiple opinions, the present study has used the hesitant fuzzy methodology [6-8]. 


\subsection{Methodology}

Several real-world problems are sorted by MCDM solutions instead of classic real-time solutions. Durability of web applications perfectly suits this category. AHP is preferred over the other MCDM techniques because the computed solutions derived from AHP are precise and effective [7]. Sometimes during the process of decision making, the experts may need more specific values for reference. Such a scenario affects the calculated results even more strongly. To address this concern in the present analysis, the authors have used a hybrid technique associating hesitant fuzzy with the AHP technique for prioritizing. Furthermore, TOPSIS methodology has been used for testing the obtained results of web application's durability. Moreover, the hesitant fuzzy technique is adopted by this paper to get more effective and precise results. If we look beyond the various available techniques of MCDM, TOPSIS methodology is the only one which gives an ideal solution path and effective results for testing [8]. To provide conclusive and ideal solution, TOPSIS methodology considers the positive as well as negative aspects at the same time, and then critically evaluates the numerical assessment.

At the point where the decision makers had to choose undefined value of numbers and numbers that were not involved in the assessment previously, the authors adopted the hesitant fuzzy set approach [6]. Hesitant fuzzy set concept was firstly proposed by Torra and Narukawa [21] and discussed and updated by Rodriguez et al. [22,23] in their further research. Thereafter, hesitant fuzzy sets have been adopted in various research pursuits in the recent years.

Wang et al. proposed a TOPSIS integrated methodology in cloud-based security architecture that produced efficient outcomes [11]. The adopted methodology for this paper has the ability to manage ambiguities and other issues of the AHP-TOPSIS methodology. Moreover, the model also validates its results by evaluating stock selection in paper. Similarly, Beg and Rashid also used the same methodology in their paper [24]. By critically analyzing the real time projects of a hospital, the authors corroborated the reliability of this approach. Moreover in the context of energy solution, $\mathrm{Xia}$ and $\mathrm{Xu}$ [25] also employed the stated methodology to produce convincing outcomes for their paper.

Hesitant Fuzzy-AHP (HF-AHP) methods have been enlisted in our study to estimate the priority of durability characteristics in web applications, and then by using HF-TOPSIS methodology, we have assessed their testing and effect on alternatives for similar characteristics. A step-by-step description of the methodology in brief is listed below:

Step 1: Hierarchy development of characteristics is the first step for methodology application.

Step 2: Examiners use linguistic terms in Table 1 to produce reliable and helpful evaluation criteria for the decision makers

Table 1. Scale for Hesitant Fuzzy-Analytic Hierarchy Process (HF-AHP) technique.

\begin{tabular}{cccc}
\hline Rank & Linguistic Term & Abbreviation & $\begin{array}{c}\text { Triangular Hesitant } \\
\text { Fuzzy Number }\end{array}$ \\
\hline 10 & Absolutely High Importance & AHI & $(7.0000,9.0000,9.0000)$ \\
9 & Very High Importance & VHI & $(5.0000,7.0000,9.0000)$ \\
8 & Essentially High Importance & ESHI & $(3.0000,5.0000,7.0000)$ \\
7 & Weakly High Importance & WHI & $(1.0000,3.0000,5.0000)$ \\
6 & Equally High Importance & EHI & $(1.0000,1.0000,3.0000)$ \\
5 & Exactly Equal & EE & $(1.0000,1.0000,1.0000)$ \\
4 & Equally Low Importance & ELI & $(0.3300,1.0000,1.0000)$ \\
3 & Weakly Low Important & WLI & $(0.2000,0.3300,1.0000)$ \\
2 & Essentially Low Importance & ESLI & $(0.1400,0.2000,0.3300)$ \\
1 & Very Low Importance & VLI & $(0.1100,0.1400,0.2000)$ \\
0 & Absolutely Low Importance & ALI & $(0.1100,0.1100,0.1400)$ \\
\hline
\end{tabular}


Step 3: Adoption of fuzzy wrappers [21,22] from Equation (1) is the next step in methodology assessment.

$$
\mathrm{OWA}\left(a_{1}, a_{2}, \ldots a_{n}\right)=\sum_{j=1}^{n} W_{j} b_{j}
$$

where OWA is denoted as ordered weighted averaging method, $W$ is for weight of characteristics. Similarly, after applying Equation (1), examiners find the trapezoidal numbers $\widetilde{C}=(\boldsymbol{a}, \boldsymbol{b}, \boldsymbol{c}, \boldsymbol{d})$ through Equations (2)-(5).

$$
\begin{aligned}
& a=\min \left\{a_{L^{\prime}}^{i}, a_{M^{\prime}}^{i} a_{M}^{i+1}, \ldots \ldots a_{M^{\prime}}^{j} a_{R}^{j}\right\}=a_{L}^{i} \\
& d=\max \left\{a_{L^{\prime}}^{i}, a_{M^{\prime}}^{i} a_{M}^{i+1}, \ldots \ldots a_{M^{\prime}}^{j}, a_{R}^{j}\right\}=a_{R}^{j}
\end{aligned}
$$

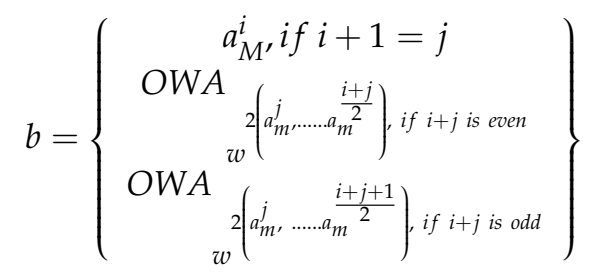

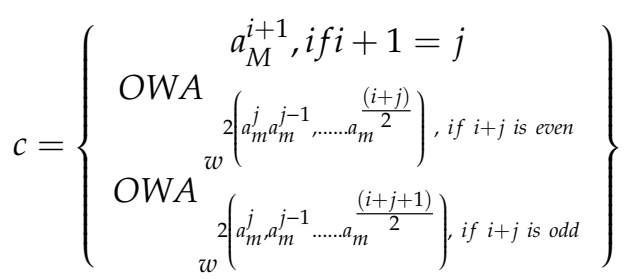

After applying the Equations (3)-(5), the examiners determine the first and second type of weights $\eta$. This is a number that lies between $[0,1]$ and to achieve these numbers, the examiners apply Equations (6) and (7).

1st type weights $\left(W 1=\left(w_{1}^{1}, w_{2}^{1}, \ldots \ldots . . . w_{n}^{1}\right)\right)$ :

$$
w_{1}^{1}=\eta_{2}, w_{2}^{1}=\eta_{2}\left(1-\eta_{2}\right), \ldots \ldots w_{n}^{1} \eta_{2}\left(1-\eta_{2}\right)^{n-2}
$$

2nd type weights $\left(\mathrm{W} 2=\left(w_{1}^{2}, w_{2}^{2}, \ldots \ldots . . . w_{n}^{2}\right)\right)$ :

$$
w_{1}^{2}=\eta_{1}^{n-1}, w_{2}^{2}=\left(1-\eta_{1}\right) \eta_{1}^{n-1}
$$

In the formula $\eta_{1}=\frac{g-(j-1)}{g-1} \mathrm{~s}$, and $\eta_{2}=\frac{g-(j-1)}{g-1}$ the numerical form for highest rank number is $g$, and lowest and highest rank characteristics are shown by $i$ and $j$, respectively.

Step 4: After analyzing the whole previous process to fulfill the remaining attributes of comparison matrix, Equations (8) and (9) are used by the examiners. Thereafter, for identifying the comparison matrix, examiners use Equation (10) to defuzzify the matrix.

$$
\begin{gathered}
\tilde{A}=\left[\begin{array}{ccc}
1 & \cdots & \tilde{c}_{1 n} \\
\vdots & \ddots & \vdots \\
\tilde{c}_{n 1} & \ldots & 1
\end{array}\right] \\
\tilde{c}_{j i}=\left(\frac{1}{c i j_{u}}, \frac{1}{c i j_{m 2}}, \frac{1}{c i j_{m 1}}, \frac{1}{c i j_{1}}\right) \\
\mu_{x}=\frac{l+2 m_{1}+2 m_{2}+h}{6}
\end{gathered}
$$

In the equation above $\left(l, m_{1}, m_{2}, h\right)$ represents lower bound, upper middle bound, lower middle bound, and higher bound of the trapezoidal number. Defuzzification step gives precise values. 
To analyze the Consistency Ratio (CR) of these values, the examiners evaluate the CR by applying Formulas (11) and (12).

$$
\begin{gathered}
C I=\frac{\gamma_{\max }-n}{n-1} \\
C R=\frac{C I}{R I}
\end{gathered}
$$

where $R I$ is random index defined in Saaty [26]

Step 6: In this step, the examiners evaluate the geometrical mean of the values through Formula (13).

$$
\tilde{r}_{i}=\left(\tilde{c}_{i 1} \otimes \tilde{c}_{i 2} \ldots \ldots \otimes \tilde{c}_{i n}\right)^{\frac{1}{n}}
$$

Step 7: Examiners assess the most significant criterion in the entire set by applying the formula of:

$$
\widetilde{w}_{i}=\tilde{r}_{1} \otimes\left(\tilde{r}_{1} \otimes \tilde{r}_{2} \ldots \ldots . \tilde{r}_{n}\right)^{-1}
$$

Step 8: Examiners analyze the defuzzified values by (15).

$$
\mu_{x}=\frac{l+2 m_{1}+2 m_{2}+h}{6}
$$

Step 9: Examiners convert the defuzzified values into normalized values or weights by applying the Formula (16).

$$
\frac{\widetilde{w}_{i}}{\sum_{i} \sum_{j} \widetilde{w}_{j}}
$$

After obtaining the priority list of durability characteristics through AHP methodology, the effectiveness of the drafted list of selected alternatives is estimated by the TOPSIS method. As a MADM technique, TOPSIS is more conclusive in suggesting the most preferred alternative for use. Lai et al. introduced the concept of TOPSIS methodology to the world and discussed it critically [27]. The present study uses the hesitant fuzzy AHP TOPSIS methodology to analyze and evaluate the web application's durability [22,27]. TOPSIS approach associates and performs its computation on the distance between two linguistic values like H1s and H2s. The process has been elucidated below:

$$
d(H 1 s, H 2 s)=\left|q^{*}-q\right|+\left|p^{*}-p\right|
$$

Step 10: As starting process following terms are defined:

- To define alternatives and criteria in TOPSIS, the following written formulas are applied as $\left(C=\left\{C_{1}, C_{2}, \ldots . C_{E}\right\}\right)$ and $n$ criteria $\left(C=\left\{C_{1}, C_{2}, \ldots . C_{n}\right\}\right)$

- $\quad e_{x}$ Denotes the experts in TOPSIS, similarly, $k$ is used to display numeric count of experts.

- In TOPSIS methodology, the equation $\widetilde{X}^{l}=\left[H_{S_{i j}}^{l}\right]_{E \times n}$ is used to represent HF matrix.

- To evaluate the criteria and effect of outcomes, the standards are written for TOPSIS are:

The standard for TOPSIS assessment lies in between very bad to highly good scale,

$r_{1}^{1}=$ between medium and good (bt M\&G)

$r_{2}^{1}=$ at most medium (am M)

$r_{1}^{2}=$ at least good (al G)

$r_{2}^{2}=$ between very bad and medium (bt VB\&M)

For HF matrix, the following formulas are used [6]:

$\operatorname{env}_{F}(E G H(b t M \& G))=T(0.3300,0.5000,0.6700,0.8300)$

$\operatorname{env}_{F}(E G H(a m M))=T(0.0000,0.0000,0.3500,0.6700)$ 
$\operatorname{env}_{F}(E G H(a l G))=T(0.5000,0.8500,1.0000,1.0000)$

$e n v_{F}(E G H(b t V B \& M))=T(0.0000,0.3000,0.3700,0.6700)$

Step 11: The associated combined matrix is created by applying the following (18) formula:

$$
\begin{aligned}
& T_{p i j}=\min \left\{\min _{i=1}^{K}\left(\max _{t_{i j}}^{x}\right), \max { }_{i=1}^{K}\left(\min H_{t_{i j}}^{x}\right)\right\} \\
& T_{q i j}=\max \left\{\min _{i=1}^{K}\left(\max _{t_{i j}}^{x}\right), \max K{ }_{i=1}^{K}\left(\min H_{t_{i j}}^{x}\right)\right\}
\end{aligned}
$$

Step 12: $\alpha_{b}$ in TOPSIS evaluation shows the effective factor where most effective factor is indicated by $\mathrm{A} \mathbf{j}$, and $\alpha_{c}$ illustrates the cost related preferences. Additionally, for cost related preferences, the lowest effective alternatives demand high accuracy. To describe and assess cost as well as effective characteristics, the following equations are employed:

$$
\begin{aligned}
& \widetilde{V}_{p j}^{+}=\max _{i=1}^{K}\left(\max _{i}\left(\min _{S_{i j}}^{x}\right)\right) j \in \alpha_{b} \text { and } \min _{i=1}^{K}\left(\min _{i}\left(\min _{S_{i j}}^{x}\right)\right) j \in \alpha_{c} \\
& \widetilde{V}_{q j}^{+}=\max _{i=1}^{K}\left(\max _{i}\left(\min _{S_{i j}}^{x}\right)\right) j \in \alpha_{b} \text { and } \min _{i=1}^{K}\left(\min _{i}\left(\min _{S_{i j}}^{x}\right)\right) j \in \alpha_{c} \\
& \widetilde{V}_{p j}^{-}=\max _{i=1}^{K}\left(\max _{i}\left(\min _{S_{i j}}^{x}\right)\right) j \in \alpha_{c} \text { and } \min _{i=1}^{K}\left(\min _{i}\left(\min _{S_{i j}}^{x}\right)\right) j \in \alpha_{b} \\
& \widetilde{V}_{q j}^{-}=\max _{i=1}^{K}\left(\max _{i}\left(\min _{S_{i j}}^{x}\right)\right) j \in \alpha_{c} \text { and } \min _{i=1}^{K}\left(\min _{i}\left(\min _{S_{i j}}^{x}\right)\right) j \in \alpha_{b}
\end{aligned}
$$

Step 13: Examiners analyze the +ve and -ve idea aspects of TOPSIS by applying following Formulas (22) and (23),

$$
\begin{gathered}
D^{+}=\left[\begin{array}{lll}
d\left(x_{11}, \widetilde{V}_{1}^{+}\right)+ & d\left(x_{12}, \widetilde{V}_{2}^{+}\right)+ & \ldots+d\left(x_{1 n}, \widetilde{V}_{n}^{+}\right) \\
d\left(x_{21}, \widetilde{V}_{1}^{+}\right)+ & d\left(x_{22}, \widetilde{V}_{2}^{+}\right)+ & \ldots+d\left(x_{21}, \widetilde{V}_{n}^{+}\right) \\
d\left(x_{m 1}, \widetilde{V}_{1}^{+}\right)+ & d\left(x_{m 2}, \widetilde{V}_{1}^{+}\right)+ & \ldots+d\left(x_{m n}, \widetilde{V}_{n}^{+}\right)
\end{array}\right] \\
D^{-}=\left[\begin{array}{ccc}
d\left(x_{11}, \widetilde{V}_{1}^{-}\right)+ & d\left(x_{12}, \widetilde{V}_{2}^{-}\right)+ & \ldots+d\left(x_{1 n}, \widetilde{V}_{n}^{-}\right) \\
d\left(x_{21}, \widetilde{V}_{1}^{-}\right)+ & d\left(x_{22}, \widetilde{V}_{2}^{-}\right)+ & \ldots+d\left(x_{21}, \widetilde{V}_{n}^{-}\right) \\
d\left(x_{m 1}, \widetilde{V}_{1}^{-}\right)+ & d\left(x_{m 2}, \widetilde{V}_{1}^{-}\right)+ & \ldots+d\left(x_{m n}, \widetilde{V}_{n}^{-}\right)
\end{array}\right]
\end{gathered}
$$

Step 14: Examiners construct and evaluate the closeness for analyzed positive and negative aspects by (24),

$$
C S\left(A_{i}\right)=\frac{D_{i}^{+}}{D_{i}^{+}+D_{i}^{-}}, i=1,2, \ldots m
$$

where

$$
D_{i}^{+}=\sum_{j=1}^{n} d\left(x_{i j}, V_{j}^{+}\right) \text {and } D_{i}^{-}=\sum_{j=1}^{n} d\left(x_{i j}, V_{j}^{-}\right)
$$

Step 15: To conclude the process, the ranks are assigned and the tabular form of alternatives are based on their effectiveness evaluation.

A thoroughly detailed and analyzed numerical assessment of web application's durability has been performed in further sections of this paper.

\section{Data Analysis and Results}

Durability is a vast and complex topic that demands numerical assessment for its effective implementation. Maintenance is the key concept for durable web applications. The current demand in web application development needs a strategic design which can meet the users' satisfaction while ensuring low maintenance cost and high service life. Despite the efforts undertaken in this regard, 
a lot needs to be done to optimize durability of web applications. Several researchers are working on web application development with long service life and other characteristics [28]. In this league, the present study assessed the various aspects of durability in web application development by using HF-AHP-TOPSIS technique. Numerical assessment of the same has been detailed below:

As a first step, the authors identified and created a hierarchical format of various durability characteristics for web application longevity (Figure 1). For evaluating the durability of web application, four characteristics at level-1 namely dependability, trustworthiness, human trust and usability are indicated as $\mathrm{C} 1, \mathrm{C} 2$, and C3, respectively. With respect to durability estimation of web application at level-2: The characteristics of dependability are confidentiality, reliability, maintainability, accountability and accessibility and are indicated as C11, C12, C13, C14, and C15, respectively. The characteristics of trustworthiness are maintainability, accountability, survivability, availability and accessibility and are indicated as C21, C22, C23, C24, and C25, respectively. The characteristics of human trust are confidentiality, consumer integrity, reliability, maintainability and user satisfaction and are represented as C31, C32, C33, C34, and C35, respectively. The characteristics of usability are maintainability, survivability, availability, accessibility and user satisfaction and are indicated as C41, C42, C43, C44, and C45, respectively. Then, to estimate the numerical assessment of these characteristics, the study garnered the opinions (with the help of virtual environment) of 110 experts who were from academics and industry. These experts had varying degrees of experience in the field of web application security; ranging from 2 to 10 years. Thereafter, the authors estimated the durability of web application by applying Equations (1)-(26).

With the help of Equations (1)-(9) and Table 1, authors transformed the linguistic values into numeric values and then hesitant fuzzy based crisp numerical values and created pair-wise comparison matrixes. With the help of Equations (10)-(16), the authors transformed the pair-wise comparison matrixes into combined values through defuzzification processes and also the consistency ratio has been calculated. The calculated values of trapezoidal fuzzy number, defuzzification values and finalized values of the weights at level 1 and level 2 are shown in Table 2.

Table 2. Global weights through the hierarchy.

\begin{tabular}{|c|c|c|c|c|c|c|}
\hline $\begin{array}{c}\text { Characteristics } \\
\text { of Level } 1\end{array}$ & $\begin{array}{c}\text { Local } \\
\text { Weights }\end{array}$ & $\begin{array}{c}\text { Characteristics } \\
\text { of Level } 2\end{array}$ & $\begin{array}{c}\text { Local } \\
\text { Weights }\end{array}$ & $\begin{array}{c}\text { Global } \\
\text { Weights }\end{array}$ & $\begin{array}{l}\text { Defuzzified } \\
\text { Weights }\end{array}$ & $\begin{array}{c}\text { Normalized } \\
\text { Weights }\end{array}$ \\
\hline \multirow{5}{*}{$\mathrm{C} 1$} & \multirow{5}{*}{$\begin{array}{l}0.03000 \\
0.08000 \\
0.09000 \\
0.15000\end{array}$} & C11 & $\begin{array}{l}0.07600 \\
0.21800 \\
0.45500 \\
1.03100\end{array}$ & $\begin{array}{l}0.00228 \\
0.01744 \\
0.04095 \\
0.15465\end{array}$ & 0.04562 & 0.051725 \\
\hline & & $\mathrm{C} 12$ & $\begin{array}{l}0.03500 \\
0.09700 \\
0.19800 \\
0.51300\end{array}$ & $\begin{array}{l}0.00105 \\
0.00776 \\
0.01782, \\
0.07695\end{array}$ & 0.02153 & 0.024408 \\
\hline & & C13 & $\begin{array}{l}0.05900 \\
0.20800 \\
0.34800 \\
1.26300\end{array}$ & $\begin{array}{l}0.00177 \\
0.01664, \\
0.03132, \\
0.18945\end{array}$ & 0.04786 & 0.054263 \\
\hline & & $\mathrm{C} 14$ & $\begin{array}{l}0.03500 \\
0.09700 \\
0.19800 \\
0.51300\end{array}$ & $\begin{array}{l}0.00105 \\
0.00776 \\
0.01782 \\
0.07695\end{array}$ & 0.02153 & 0.024408 \\
\hline & & C15 & $\begin{array}{l}0.03100 \\
0.07800 \\
0.12100 \\
0.39000\end{array}$ & $\begin{array}{l}0.00093 \\
0.00624 \\
0.01089 \\
0.05850\end{array}$ & 0.01562 & 0.017705 \\
\hline
\end{tabular}


Table 2. Cont.

\begin{tabular}{|c|c|c|c|c|c|c|}
\hline $\begin{array}{c}\text { Characteristics } \\
\text { of Level } 1\end{array}$ & $\begin{array}{c}\text { Local } \\
\text { Weights }\end{array}$ & $\begin{array}{c}\text { Characteristics } \\
\text { of Level } 2\end{array}$ & $\begin{array}{c}\text { Local } \\
\text { Weights }\end{array}$ & $\begin{array}{c}\text { Global } \\
\text { Weights }\end{array}$ & $\begin{array}{c}\text { Defuzzified } \\
\text { Weights }\end{array}$ & $\begin{array}{c}\text { Normalized } \\
\text { Weights }\end{array}$ \\
\hline \multirow[t]{5}{*}{$\mathrm{C} 2$} & \multirow[t]{5}{*}{$\begin{array}{l}0.11000, \\
0.28000 \\
0.33000 \\
0.51000\end{array}$} & C21 & $\begin{array}{l}0.03500 \\
0.09700 \\
0.19800 \\
0.51300\end{array}$ & $\begin{array}{l}0.00385 \\
0.02716 \\
0.06534 \\
0.26163\end{array}$ & 0.07508 & 0.085130 \\
\hline & & $\mathrm{C} 22$ & $\begin{array}{l}0.03300 \\
0.12900 \\
0.21200 \\
0.78100\end{array}$ & $\begin{array}{l}0.00363 \\
0.03612 \\
0.06996 \\
0.39831\end{array}$ & 0.10235 & 0.116051 \\
\hline & & $\mathrm{C} 23$ & $\begin{array}{l}0.03100 \\
0.07800 \\
0.12100 \\
0.39000\end{array}$ & $\begin{array}{l}0.00341, \\
0.02184, \\
0.03993, \\
0.19890\end{array}$ & 0.05431 & 0.061578 \\
\hline & & $\mathrm{C} 24$ & $\begin{array}{l}0.03500 \\
0.09070 \\
0.19080 \\
0.51300\end{array}$ & $\begin{array}{l}0.00385 \\
0.02540 \\
0.06296 \\
0.26160\end{array}$ & 0.07370 & 0.083566 \\
\hline & & $\mathrm{C} 25$ & $\begin{array}{l}0.02200 \\
0.07300 \\
0.11300 \\
0.50300\end{array}$ & $\begin{array}{l}0.00242, \\
0.02044 \\
0.03729 \\
0.25653\end{array}$ & 0.06240 & 0.070755 \\
\hline \multirow{5}{*}{ C3 } & \multirow{5}{*}{$\begin{array}{l}0.07000 \\
0.12000 \\
0.13000 \\
0.25000\end{array}$} & C31 & $\begin{array}{l}0.07600 \\
0.21800 \\
0.45500 \\
1.03100\end{array}$ & $\begin{array}{l}0.00532, \\
0.02616 \\
0.05915, \\
0.25775\end{array}$ & 0.07228 & 0.081957 \\
\hline & & C32 & $\begin{array}{l}0.03500 \\
0.09700 \\
0.19800 \\
0.51300\end{array}$ & $\begin{array}{l}0.00245 \\
0.01164, \\
0.02574, \\
0.12825\end{array}$ & 0.03424 & 0.038827 \\
\hline & & C33 & $\begin{array}{l}0.07600 \\
0.21800 \\
0.45050 \\
1.03100\end{array}$ & $\begin{array}{l}0.00532, \\
0.02616 \\
0.05857 \\
0.25775\end{array}$ & 0.07209 & 0.081736 \\
\hline & & C34 & $\begin{array}{l}0.03100 \\
0.07800 \\
0.12100 \\
0.39000\end{array}$ & $\begin{array}{l}0.00217 \\
0.00936 \\
0.01573 \\
0.09750\end{array}$ & 0.02498 & 0.028318 \\
\hline & & C35 & $\begin{array}{l}0.03500 \\
0.09700 \\
0.19800 \\
0.51300\end{array}$ & $\begin{array}{l}0.00245 \\
0.01164 \\
0.02574 \\
0.12825\end{array}$ & 0.03424 & 0.038827 \\
\hline \multirow[b]{2}{*}{$\mathrm{C} 4$} & \multirow{2}{*}{$\begin{array}{l}0.04000 \\
0.04000 \\
0.05000 \\
0.11000\end{array}$} & C41 & $\begin{array}{l}0.03100 \\
0.07800 \\
0.12100 \\
0.39000\end{array}$ & $\begin{array}{l}0.00124, \\
0.00312, \\
0.00605, \\
0.04290\end{array}$ & 0.01041 & 0.011807 \\
\hline & & C42 & $\begin{array}{l}0.03500 \\
0.09700 \\
0.19800 \\
0.51300\end{array}$ & $\begin{array}{l}0.00140 \\
0.00388 \\
0.00990 \\
0.05643\end{array}$ & 0.01423 & 0.016137 \\
\hline
\end{tabular}


Table 2. Cont.

\begin{tabular}{|c|c|c|c|c|c|c|}
\hline $\begin{array}{c}\text { Characteristics } \\
\text { of Level } 1\end{array}$ & $\begin{array}{c}\text { Local } \\
\text { Weights }\end{array}$ & $\begin{array}{c}\text { Characteristics } \\
\text { of Level } 2\end{array}$ & $\begin{array}{c}\text { Local } \\
\text { Weights }\end{array}$ & $\begin{array}{c}\text { Global } \\
\text { Weights }\end{array}$ & $\begin{array}{c}\text { Defuzzified } \\
\text { Weights }\end{array}$ & $\begin{array}{c}\text { Normalized } \\
\text { Weights }\end{array}$ \\
\hline & & $\mathrm{C} 43$ & $\begin{array}{l}0.12000 \\
0.26000 \\
0.58000 \\
1.43000\end{array}$ & $\begin{array}{l}0.00480 \\
0.01040 \\
0.02900 \\
0.15730\end{array}$ & 0.04015 & 0.045525 \\
\hline & & $\mathrm{C} 44$ & $\begin{array}{l}0.06000 \\
0.12000 \\
0.40000 \\
0.60000\end{array}$ & $\begin{array}{l}0.00240 \\
0.00480 \\
0.02000 \\
0.06600\end{array}$ & 0.019667 & 0.022299 \\
\hline & & C45 & $\begin{array}{l}0.12000 \\
0.25000 \\
0.57000 \\
1.42000\end{array}$ & $\begin{array}{l}0.00480 \\
0.01000 \\
0.02850 \\
0.15620\end{array}$ & 0.039667 & 0.044977 \\
\hline
\end{tabular}

Table 2 depicts that the level 2 of the hierarchy shows various characteristics that affect its greater level characteristics but their effect for every single factor is different from others. In this type of situation, the authors grouped the characteristics for effective results. Evaluation of alternatives to test the obtained results is shown in following Tables 3 and 4.

Table 3. Dependent weights of level 1 attributes.

\begin{tabular}{|c|c|c|c|c|c|}
\hline S. No. & $\begin{array}{c}\text { Characteristics } \\
\text { of Level } 1\end{array}$ & $\begin{array}{c}\text { Global } \\
\text { Weights }\end{array}$ & $\begin{array}{l}\text { Defuzzified } \\
\text { Weights }\end{array}$ & $\begin{array}{c}\text { Normalized } \\
\text { Weights }\end{array}$ & \\
\hline 1 & Dependability & $\begin{array}{l}0.03000 \\
0.08000 \\
0.09000 \\
0.15000\end{array}$ & 0.0866666667 & 0.148148148 & $\mathrm{C} 1$ \\
\hline 2 & Trustworthiness & $\begin{array}{l}0.11000 \\
0.28000 \\
0.33000 \\
0.51000\end{array}$ & 0.306666667 & 0.524216524 & $\mathrm{C} 2$ \\
\hline 3 & Human Trust & $\begin{array}{l}0.07000 \\
0.12000 \\
0.13000 \\
0.25000\end{array}$ & 0.136666667 & 0.233618234 & $\mathrm{C} 3$ \\
\hline 4 & Usability & $\begin{array}{l}0.04000 \\
0.04000 \\
0.05000 \\
0.11000\end{array}$ & 0.055000000 & 0.094017094 & $\mathrm{C} 4$ \\
\hline
\end{tabular}

This portion of the section provides a realistic assessment of evaluated results on highly sensitive web applications of the University. Further, to analyze the hesitant fuzzy TOPSIS methodology, the authors selected 6 different web application projects of BBA University (India) $[6,8]$ that are represented by $A V 1, A V 2, A V 3, A V 4, A V 5$, and $A V 6$ for assessment. With the help of the Equation (17) and step 10, authors took the inputs on the technical data of six projects of the University. Table 5 below illustrates the results in a combinative manner. Tables 6 and 7 portray the normalized and weighted normalized values of alternatives in perspective of durability characteristics with the help of the Equations (18)-(24). According to Table 6, maintainability (with the weight 0.1795) has the highest weightage in estimation of durability of web application. While, as per Table 3 , trustworthiness with the weight of 0.5242 , has the highest priority among level 1 characteristics. This suggests that while designing a durable web application, developer should focus on trustworthiness and maintainability. This will lead to a more durable web application. Lastly, satisfaction degrees of different alternatives are estimated with the help of Equations (25) and (26), as shown in Table 8 and Figure 2. 
Table 4. Dependent weights of level 2 attributes.

\begin{tabular}{|c|c|c|c|c|c|}
\hline S. No. & Characteristics of Level 2 & $\begin{array}{c}\text { Global } \\
\text { Weights }\end{array}$ & $\begin{array}{l}\text { Defuzzified } \\
\text { Weights }\end{array}$ & $\begin{array}{c}\text { Normalized } \\
\text { Weights }\end{array}$ & \\
\hline 1 & Confidentiality & $\begin{array}{l}0.00760 \\
0.04360 \\
0.10010 \\
0.41240\end{array}$ & 0.117900 & 0.133682 & $\mathrm{C} 11+\mathrm{C} 31$ \\
\hline 2 & Consumer Integrity & $\begin{array}{l}0.00245 \\
0.01164 \\
0.02574 \\
0.12825\end{array}$ & 0.034243 & 0.038827 & C32 \\
\hline 3 & Reliability & $\begin{array}{c}0.00637 \\
0.03392, \\
0.076385 \\
0.3347\end{array}$ & 0.093613 & 0.106145 & $\mathrm{C} 12+\mathrm{C} 33$ \\
\hline 4 & Maintainability & $\begin{array}{l}0.00903 \\
0.05628 \\
0.11844 \\
0.59148\end{array}$ & 0.158325 & 0.179519 & $\mathrm{C} 13+\mathrm{C} 21+\mathrm{C} 34+\mathrm{C} 41$ \\
\hline 5 & Accountability & $\begin{array}{l}0.00468 \\
0.04388 \\
0.08778 \\
0.47526\end{array}$ & 0.123877 & 0.140459 & $\mathrm{C} 14+\mathrm{C} 22$ \\
\hline 6 & Survivability & $\begin{array}{l}0.00481 \\
0.02572 \\
0.04983 \\
0.25533\end{array}$ & 0.068540 & 0.077715 & $\mathrm{C} 23+\mathrm{C} 42$ \\
\hline 7 & Availability & $\begin{array}{c}0.00865 \\
0.035796 \\
0.091964 \\
0.41893\end{array}$ & 0.113850 & 0.129090 & $\mathrm{C} 24+\mathrm{C} 43$ \\
\hline 8 & Accessibility & $\begin{array}{l}0.00575 \\
0.03148 \\
0.06818 \\
0.38103\end{array}$ & 0.097683 & 0.110759 & $\mathrm{C} 15+\mathrm{C} 25+\mathrm{C} 44$ \\
\hline 9 & User Satisfaction & $\begin{array}{l}0.00725 \\
0.02164 \\
0.05424 \\
0.28445\end{array}$ & 0.073910 & 0.083804 & $\mathrm{C} 35+\mathrm{C} 45$ \\
\hline
\end{tabular}

Table 5. Subjective cognition results of evaluators in linguistic terms.

\begin{tabular}{ccccccc}
\hline $\begin{array}{c}\text { Durability } \\
\text { Characteristics/Alternatives }\end{array}$ & AV1 & AV2 & AV3 & AV4 & AV5 & AV6 \\
\hline \multirow{3}{*}{ Confidentiality } & 1.1800, & 2.0900, & 2.8200, & 1.5500, & 1.4500, & 2.4500, \\
& 2.8200, & 3.7300, & 4.6400, & 3.1800, & 3.1800, & 4.2700, \\
& 4.8200, & 5.7300, & 6.6400, & 5.1800, & 5.1800, & 6.2700, \\
& 6.4500 & 6.4500 & 8.7200 & 6.7200 & 7.7200 & 8.6200 \\
Consumer Integrity & 0.8200, & 2.9100, & 1.4500, & 1.1800, & 2.0900, & 2.0900, \\
& 2.2700, & 4.6400, & 3.0000, & 2.8200, & 3.7300, & 3.7300, \\
& 4.2700, & 6.0000, & 4.9100, & 4.8200, & 5.7300, & 5.7300, \\
& 6.6500 & 6.4500 & 5.4500 & 6.4500 & 6.4500 & 6.4500 \\
Reliability & 2.4500, & 3.1800, & 1.4500, & 0.8200, & 3.0000, & 3.0000, \\
& 4.2700, & 5.1800, & 3.0700, & 2.2700, & 4.8200, & 4.8200, \\
& 6.2700, & 7.1000, & 4.9100, & 4.2700, & 6.8200, & 6.8200, \\
& 8.6500 & 8.6500 & 5.6500 & 6.6500 & 7.6500 & 7.6500 \\
Maintainability & 1.1800, & 2.4500, & 0.9100, & 2.4500, & 3.9100, & 3.9100, \\
& 2.8200, & 4.4500, & 2.4500, & 4.2700, & 5.9100, & 5.9100, \\
& 4.8200, & 6.4500, & 4.4500, & 6.2700, & 7.8200, & 7.8200, \\
& 6.4500 & 7.6500 & 5.6500 & 8.6500 & 8.6500 & 8.6500 \\
\hline
\end{tabular}


Table 5. Cont.

\begin{tabular}{ccccccc}
\hline $\begin{array}{c}\text { Durability } \\
\text { Characteristics/Alternatives }\end{array}$ & AV1 & AV2 & AV3 & AV4 & AV5 & AV6 \\
\hline \multirow{4}{*}{ Accountability } & 0.8200, & 3.0000, & 2.9100, & 1.4500, & 1.1800, & 2.0900, \\
& 2.2700, & 4.8200, & 4.6400, & 3.0000, & 2.8200, & 3.7300, \\
& 4.2700, & 6.8200, & 6.000, & 4.9100, & 4.8200, & 5.7300, \\
Survivability & 6.6500 & 7.6500 & 6.4500 & 5.4500 & 6.4500 & 6.4500 \\
& 2.4500, & 3.9100, & 3.1800, & 1.4500, & 0.8200, & 3.0000, \\
& 4.2700, & 5.9100, & 5.1800, & 3.0700, & 2.2700, & 4.8200, \\
& 6.2700, & 7.8200, & 7.1000, & 4.9100, & 4.2700, & 6.8200, \\
Availability & 8.6500 & 8.6500 & 8.6500 & 5.6500 & 6.6500 & 7.6500 \\
& 5.3600, & 3.7300, & 2.4500, & 0.9100, & 2.4500, & 3.9100, \\
& 6.3600, & 5.7300, & 4.4500, & 2.4500, & 4.2700, & 5.9100, \\
& 7.1200, & 7.5500, & 6.4500, & 4.4500, & 6.2700, & 7.8200, \\
Accessibility & 8.5100 & 8.6500 & 7.6500 & 5.6500 & 8.6500 & 8.6500 \\
& 5.1200, & 3.1500, & 2.8200, & 1.5500, & 1.4500, & 2.4500, \\
& 7.1400, & 5.1500, & 4.6400, & 3.1800, & 3.1800, & 4.2700, \\
& 7.7200, & 6.9100, & 6.6400, & 5.1800, & 5.1800, & 6.2700, \\
& 8.5900 & 7.8400 & 7.8400 & 6.5400 & 6.2500 & 8.2600 \\
User Satisfaction & 2.9100, & 1.4500, & 1.1800, & 0.9100, & 2.4500, & 3.9100, \\
& 4.6400, & 3.0000, & 2.8200, & 2.4500, & 4.2700, & 5.9100, \\
& 6.0000, & 4.9100, & 4.8200, & 4.4500, & 6.2700, & 7.8200, \\
& 6.4500 & 5.4500 & 6.4500 & 5.6500 & 8.6500 & 8.6500 \\
\hline
\end{tabular}

Table 6. The normalized fuzzy-decision matrix.

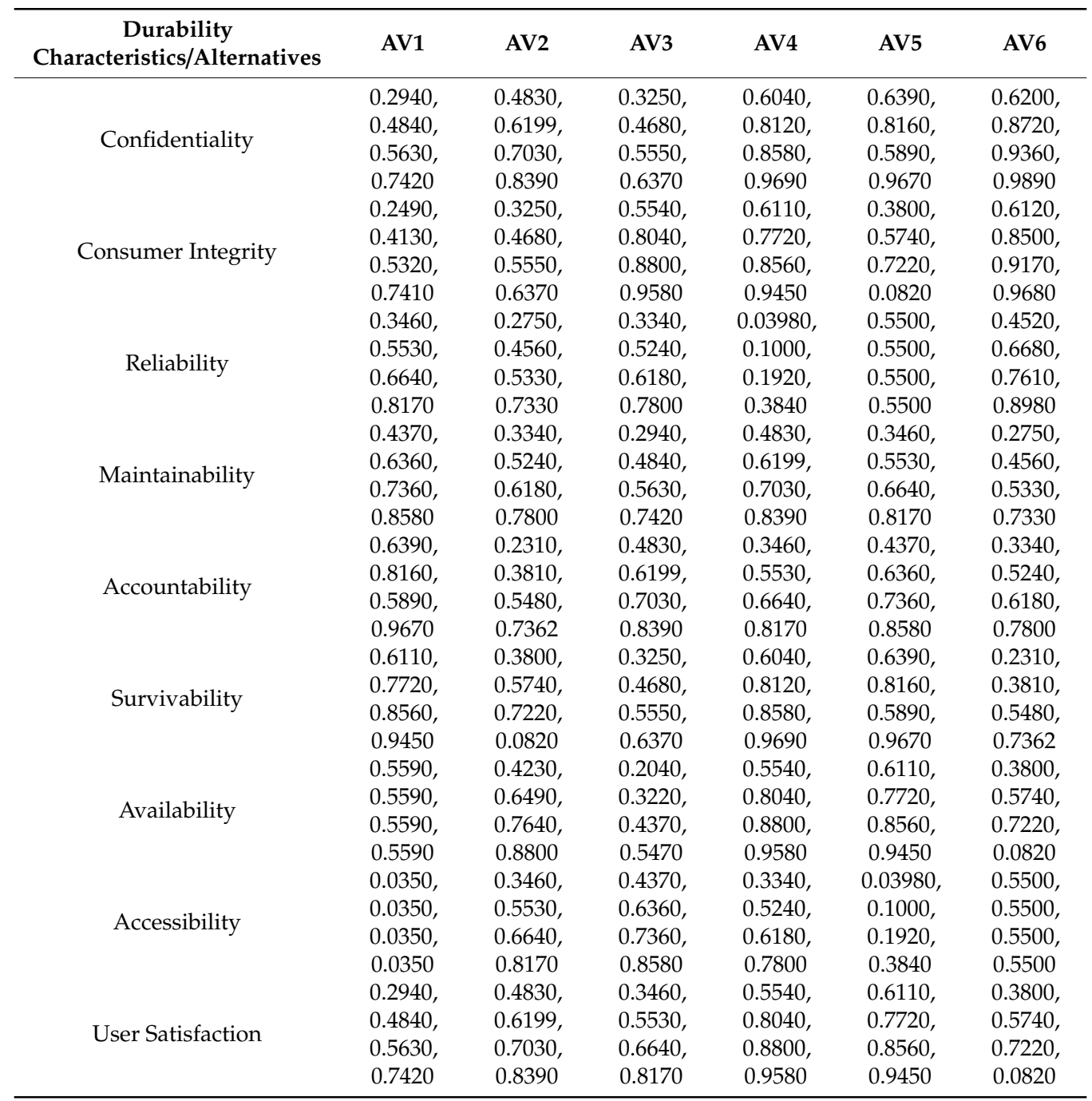


Table 7. The weighted normalized fuzzy-decision matrix.

\begin{tabular}{|c|c|c|c|c|c|c|}
\hline $\begin{array}{c}\text { Durability } \\
\text { Characteristics/Alternatives }\end{array}$ & AV1 & AV2 & AV3 & AV4 & AV5 & AV6 \\
\hline Confidentiality & $\begin{array}{l}0.0570 \\
0.0850 \\
0.1080 \\
0.1310\end{array}$ & $\begin{array}{l}0.0555 \\
0.0870 \\
0.1040 \\
0.1220\end{array}$ & $\begin{array}{l}0.0428, \\
0.0590, \\
0.0640, \\
0.0680\end{array}$ & $\begin{array}{l}0.0344 \\
0.0570 \\
0.0820 \\
0.1100\end{array}$ & $\begin{array}{l}0.0470 \\
0.0740 \\
0.0920 \\
0.1120\end{array}$ & $\begin{array}{l}0.0434, \\
0.0510, \\
0.0660, \\
0.0690\end{array}$ \\
\hline Consumer Integrity & $\begin{array}{c}0.0371 \\
0.0616 \\
0.0790 \\
0.1100\end{array}$ & $\begin{array}{l}0.0320 \\
0.0530 \\
0.0720 \\
0.0980\end{array}$ & $\begin{array}{l}0.0080, \\
0.0120, \\
0.0160, \\
0.0210\end{array}$ & $\begin{array}{c}0.1150 \\
0.1670 \\
0.1830 \\
0.1990\end{array}$ & $\begin{array}{c}0.1420 \\
0.1790 \\
0.1980 \\
0.2190\end{array}$ & $\begin{array}{l}0.0120, \\
0.0180, \\
0.0210, \\
0.0240\end{array}$ \\
\hline Reliability & $\begin{array}{l}0.0630 \\
0.0979 \\
0.1140 \\
0.1310\end{array}$ & $\begin{array}{l}0.0610 \\
0.0870 \\
0.1010 \\
0.1200\end{array}$ & $\begin{array}{l}0.0087, \\
0.0135, \\
0.0170, \\
0.0210\end{array}$ & $\begin{array}{l}0.0774 \\
0.1180 \\
0.1440 \\
0.1730\end{array}$ & $\begin{array}{l}0.0320 \\
0.0530 \\
0.0720 \\
0.0980\end{array}$ & $\begin{array}{l}0.0080, \\
0.0120, \\
0.0160, \\
0.0210\end{array}$ \\
\hline Maintainability & $\begin{array}{l}0.0120 \\
0.0180 \\
0.0210 \\
0.0240\end{array}$ & $\begin{array}{l}0.1250 \\
0.1690 \\
0.1850 \\
0.2010\end{array}$ & $\begin{array}{l}0.1480, \\
0.1891, \\
0.2060, \\
0.2240\end{array}$ & $\begin{array}{l}0.0630 \\
0.0979 \\
0.1140 \\
0.1310\end{array}$ & $\begin{array}{l}0.0610 \\
0.0870 \\
0.1010 \\
0.1200\end{array}$ & $\begin{array}{l}0.0190, \\
0.0325, \\
0.0380, \\
0.0510\end{array}$ \\
\hline Accountability & $\begin{array}{l}0.0080 \\
0.0120 \\
0.0160 \\
0.0210\end{array}$ & $\begin{array}{c}0.1150 \\
0.1670 \\
0.1830 \\
0.1990\end{array}$ & $\begin{array}{l}0.1420, \\
0.1790, \\
0.1980, \\
0.2190\end{array}$ & $\begin{array}{l}0.0120 \\
0.0180 \\
0.0210 \\
0.0240\end{array}$ & $\begin{array}{l}0.1250 \\
0.1690 \\
0.1850 \\
0.2010\end{array}$ & $\begin{array}{l}0.1480, \\
0.1891, \\
0.2060, \\
0.2240\end{array}$ \\
\hline Survivability & $\begin{array}{l}0.0854 \\
0.0930 \\
0.0930 \\
0.0986\end{array}$ & $\begin{array}{l}0.0371 \\
0.0616 \\
0.0790 \\
0.1100\end{array}$ & $\begin{array}{l}0.0320, \\
0.0530, \\
0.0720, \\
0.0980\end{array}$ & $\begin{array}{l}0.0080 \\
0.0120 \\
0.0160 \\
0.0210\end{array}$ & $\begin{array}{l}0.1150 \\
0.1670 \\
0.1830 \\
0.1990\end{array}$ & $\begin{array}{l}0.1420, \\
0.1790, \\
0.1980, \\
0.2190\end{array}$ \\
\hline Availability & $\begin{array}{l}0.0890 \\
0.0960 \\
0.0960 \\
0.1030\end{array}$ & $\begin{array}{l}0.0630 \\
0.0979 \\
0.1140 \\
0.1310\end{array}$ & $\begin{array}{l}0.0610, \\
0.0870, \\
0.1010, \\
0.1200\end{array}$ & $\begin{array}{l}0.0087 \\
0.0135 \\
0.0170 \\
0.0210\end{array}$ & $\begin{array}{l}0.0774 \\
0.1180 \\
0.1440 \\
0.1730\end{array}$ & $\begin{array}{l}0.1330, \\
0.1680, \\
0.1840, \\
0.2080\end{array}$ \\
\hline Accessibility & $\begin{array}{l}0.0010 \\
0.0060 \\
0.0060 \\
0.0130\end{array}$ & $\begin{array}{l}0.0516 \\
0.0820 \\
0.0990 \\
0.1220\end{array}$ & $\begin{array}{l}0.0580, \\
0.0850, \\
0.0950, \\
0.1180\end{array}$ & $\begin{array}{l}0.0230 \\
0.0370 \\
0.0430 \\
0.0550\end{array}$ & $\begin{array}{l}0.0090 \\
0.0230 \\
0.0450 \\
0.0590\end{array}$ & $\begin{array}{l}0.0870, \\
0.0940, \\
0.0940, \\
0.1010\end{array}$ \\
\hline User Satisfaction & $\begin{array}{l}0.0320 \\
0.0530 \\
0.0720 \\
0.0980\end{array}$ & $\begin{array}{l}0.0080 \\
0.0120 \\
0.0160 \\
0.0210\end{array}$ & $\begin{array}{l}0.1150, \\
0.1670, \\
0.1830, \\
0.1990\end{array}$ & $\begin{array}{l}0.0630 \\
0.0979 \\
0.1140 \\
0.1310\end{array}$ & $\begin{array}{l}0.0610 \\
0.0870 \\
0.1010 \\
0.1200\end{array}$ & $\begin{array}{l}0.0190, \\
0.0325, \\
0.0380, \\
0.0510\end{array}$ \\
\hline
\end{tabular}

Table 8. Closeness coefficients to the aspired level among the different alternatives.

\begin{tabular}{ccccc}
\hline \multicolumn{2}{c}{ Alternatives } & $\mathbf{d}^{\mathbf{+ i}}$ & $\mathbf{d}^{-\mathbf{i}}$ & $\boldsymbol{g}_{\boldsymbol{i}}$ \\
\hline Version 1 & AV1 & 0.16154 & 0.07965 & 0.31254 \\
Version 2 & AV2 & 0.24264 & 0.12132 & 0.32854 \\
Version 3 & AV3 & 0.24525 & 0.07524 & 0.21126 \\
Version 4 & AV4 & 0.45548 & 0.16854 & 0.27854 \\
Version 5 & AV5 & 0.48745 & 0.18123 & 0.27325 \\
Version 6 & AV6 & 0.15874 & 0.06565 & 0.28352 \\
\hline
\end{tabular}

To describe and portray the satisfaction degrees of the alternatives, $g_{i}$ is evaluated in above table. The above table illustrates the effectiveness of alternatives by numeric values. As evident, the effect of durability characteristics prioritization is in good standard by alternative assessment results. Authors strongly believe and recommend that the numeric assessment and outcome is satisfactory, and in good condition, for the BBA University projects. Moreover, the prioritized table and ranking for durability in web application is also effective. Results described in the table show that the second alternative has the highest effect than all the others. 


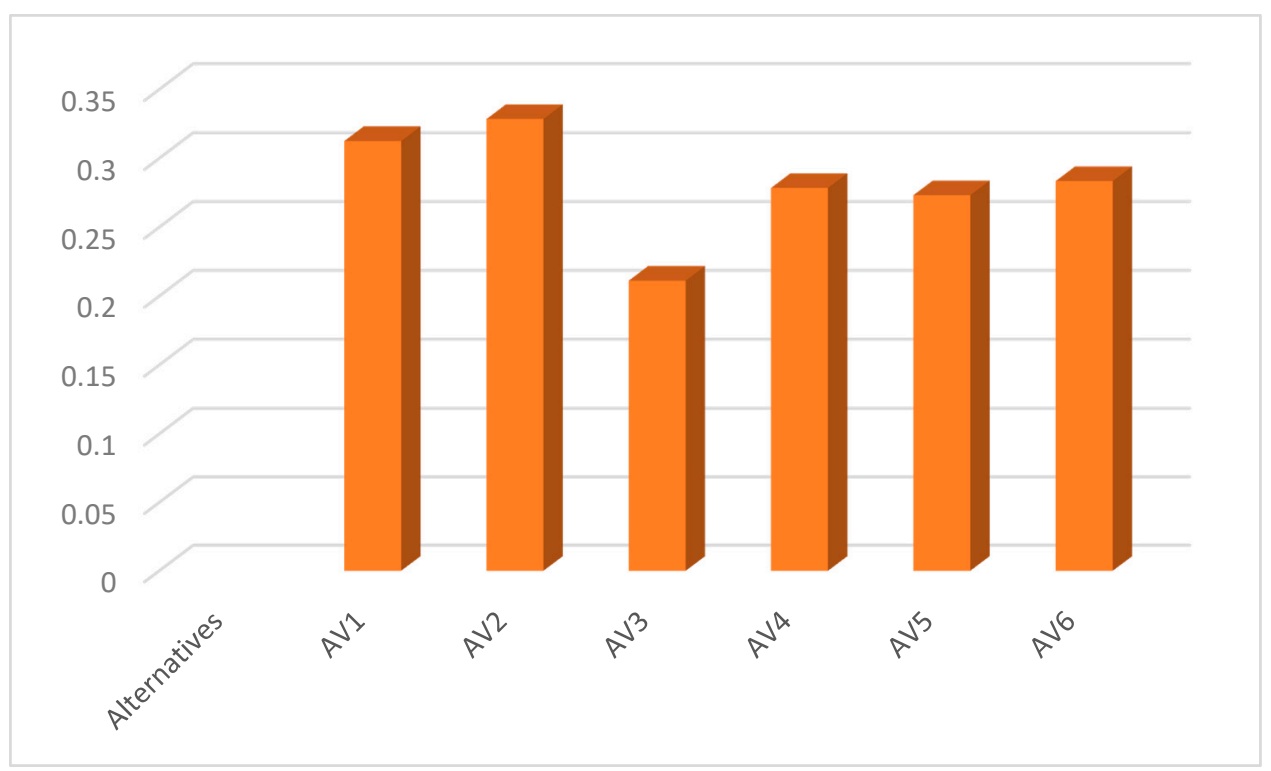

Figure 2. Graphical representation of satisfaction degree.

\subsection{Robustness Assessment}

To check the robustness of the evaluated results in this proposed article, authors conducted a robustness analysis or sensitivity analysis. Robustness, in any type of numerical assessment, is an important feature in establishing the reliability of the results and validating them for further reference. It is always beneficial to evaluate the quality of computed results for deriving at a corroborative analysis. Calculated weights are used by the authors to conduct the sensitivity analysis. In the proposed study, the authors chose 6 alternatives to perform web application durability estimation. Thus, for conducting the sensitivity analysis also, the authors selected the same 6 alternatives. A well-established robustness assessment is portrayed in the Table 9 and Figure 3.

Table 9. Sensitivity analysis.

\begin{tabular}{|c|c|c|c|c|c|c|c|c|c|c|c|}
\hline \multicolumn{2}{|c|}{ Alternatives } & 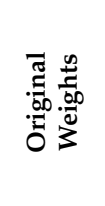 & 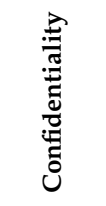 & 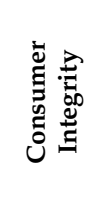 & $\begin{array}{l}\stackrel{2}{:} \\
: \frac{7}{0} \\
: \frac{\pi}{2} \\
\simeq\end{array}$ & 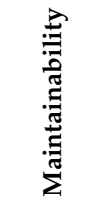 & 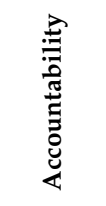 & 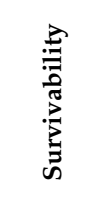 & 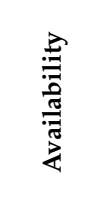 & 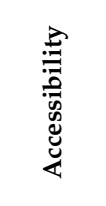 & 总 \\
\hline Version 1 & AV1 & 0.31254 & 0.35735 & 0.39869 & 0.34674 & 0.30778 & 0.31226 & 0.31457 & 0.31475 & 0.34967 & 0.32354 \\
\hline Version 2 & AV2 & 0.32854 & 0.36984 & 0.40387 & 0.35963 & 0.33254 & 0.31545 & 0.30749 & 0.31769 & 0.35859 & 0.32658 \\
\hline Version 3 & AV3 & 0.21126 & 0.25857 & 0.28747 & 0.24364 & 0.20242 & 0.21256 & 0.21749 & 0.21632 & 0.24567 & 0.25687 \\
\hline Version 4 & AV4 & 0.27854 & 0.31695 & 0.34565 & 0.30194 & 0.24823 & 0.28325 & 0.29267 & 0.28654 & 0.34524 & 0.28547 \\
\hline Version 5 & AV5 & 0.27325 & 0.31856 & 0.34887 & 0.30274 & 0.27125 & 0.27256 & 0.27267 & 0.27267 & 0.31548 & 0.25648 \\
\hline Version 6 & AV6 & 0.28352 & 0.32859 & 0.35562 & 0.36547 & 0.26945 & 0.28574 & 0.29457 & 0.28659 & 0.35687 & 0.27584 \\
\hline
\end{tabular}

The assessed results for robustness analysis conclude that alternative 2 is the most effective factor application for web application durability. In the context of robustness assessment, the primary first row of table represents real computed results. By implementing robustness analysis standards on weights for characteristics, we found that all the factor have the same higher effect as in the real assessment. Results also provide information that numeric outcomes are sensitive towards weighs of characteristics. 


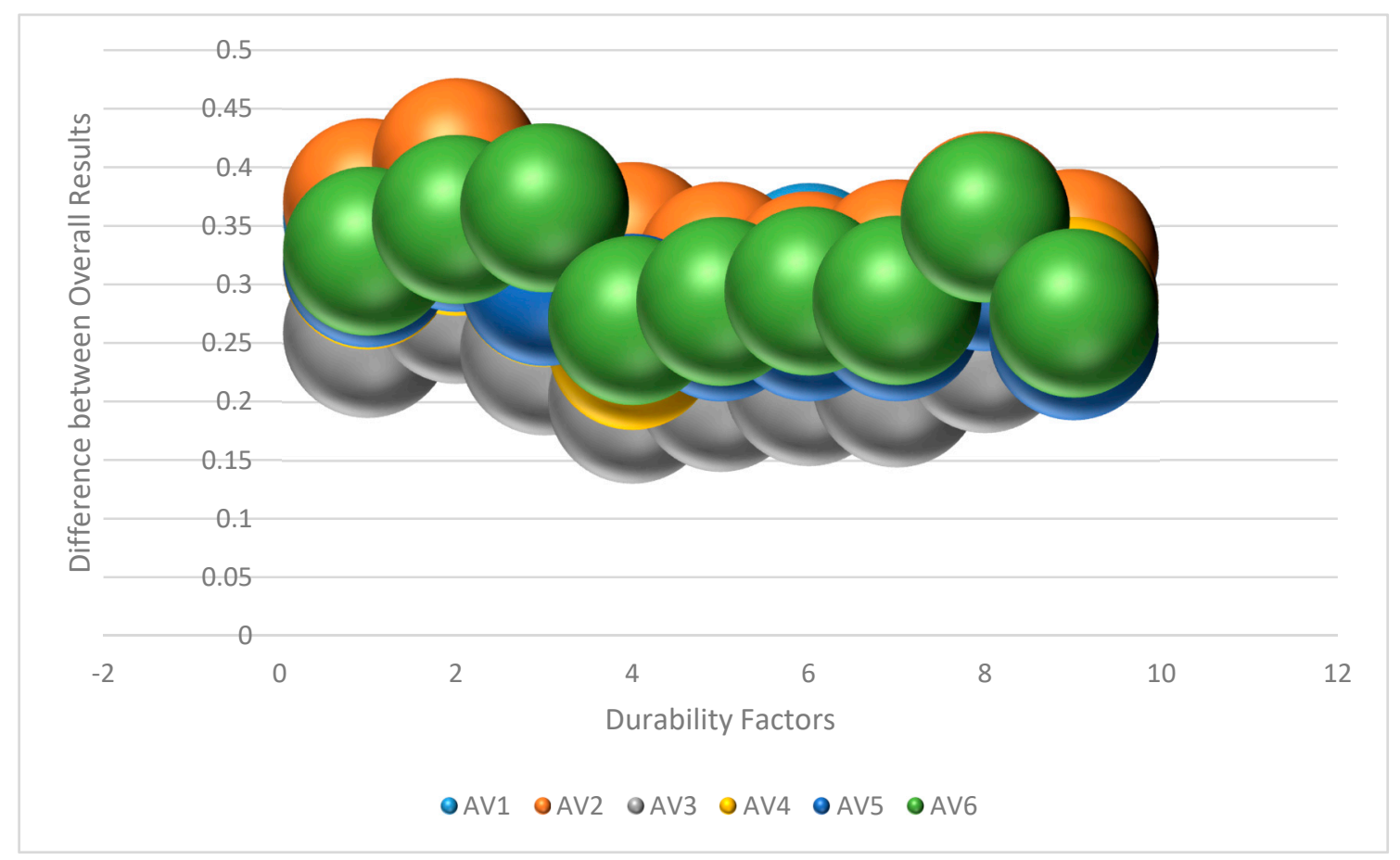

Figure 3. Graphical representation of sensitivity analysis.

\subsection{Comparison with Other Pair-Wise Techniques}

Comparing the results obtained from different methods gives an ideal understanding about the variation of numerical assessment in various techniques. We compared the hesitant fuzzy AHP-TOPSIS technique with the other four techniques of MCDM including Fuzzy AHP-TOPSIS, Fuzzy ANP-TOPSIS, Classical AHP-TOPSIS, and Classical ANP-TOPSIS for gauging the effectiveness of the proposed technique [7-10]. Although hybrid methods such as Fuzzy AHP-TOPSIS and Fuzzy ANP TOPSIS give good results, but in the current case of characteristics of web application durability, hesitant fuzzy AHP TOPSIS proves to be the accurate one [11-15]. The results obtained through the comparison were not so varied and different from each other but the accuracy of results differed from each other. The hesitant fuzzy AHP-TOPSIS technique has an advantage of assigning hesitant fuzzy set valuation in assigning values to characteristics. The calculated results are tabulated in the Table 10 and Figure 4.

Table 10. Comparison through classical AHP-TOPSIS technique.

\begin{tabular}{llccccc}
\hline \multicolumn{2}{c}{ Alternatives } & $\begin{array}{c}\text { Hesitant Fuzzy } \\
\text { AHP-TOPSIS }\end{array}$ & $\begin{array}{c}\text { Fuzzy } \\
\text { AHP-TOPSIS }\end{array}$ & $\begin{array}{c}\text { Fuzzy } \\
\text { ANP-TOPSIS }\end{array}$ & $\begin{array}{c}\text { Classical } \\
\text { AHP-TOPSIS }\end{array}$ & $\begin{array}{c}\text { Classical } \\
\text { ANP-TOPSIS }\end{array}$ \\
\hline Version 1 & AV1 & 0.31254 & 0.31002 & 0.30712 & 0.29672 & 0.31235 \\
Version 2 & AV2 & 0.32854 & 0.32003 & 0.33223 & 0.30944 & 0.31534 \\
Version 3 & AV3 & 0.21126 & 0.21002 & 0.20248 & 0.19714 & 0.21362 \\
Version 4 & AV4 & 0.27854 & 0.27004 & 0.24812 & 0.26057 & 0.28244 \\
Version 5 & AV5 & 0.27325 & 0.27006 & 0.27023 & 0.31214 & 0.27457 \\
Version 6 & AV6 & 0.28352 & 0.28001 & 0.26958 & 0.28125 & 0.28555 \\
\hline
\end{tabular}

It is shown by the Table 10 and Figure 4 that results assessed by hesitant fuzzy AHP TOPSIS methodology are more accurate than the other four techniques because of the additional facility of hesitant fuzzy set theory in the methodology. Thus, the adopted approach in this study has higher potential and gives better results.

Several research endeavors define durability in software and web applications and different perspectives on durability concept in software and web applications have been forwarded by different 
researchers $[5,6,16]$. However, authors of this study did not find a research analysis that discussed the quantitative assessment of web application's durability.

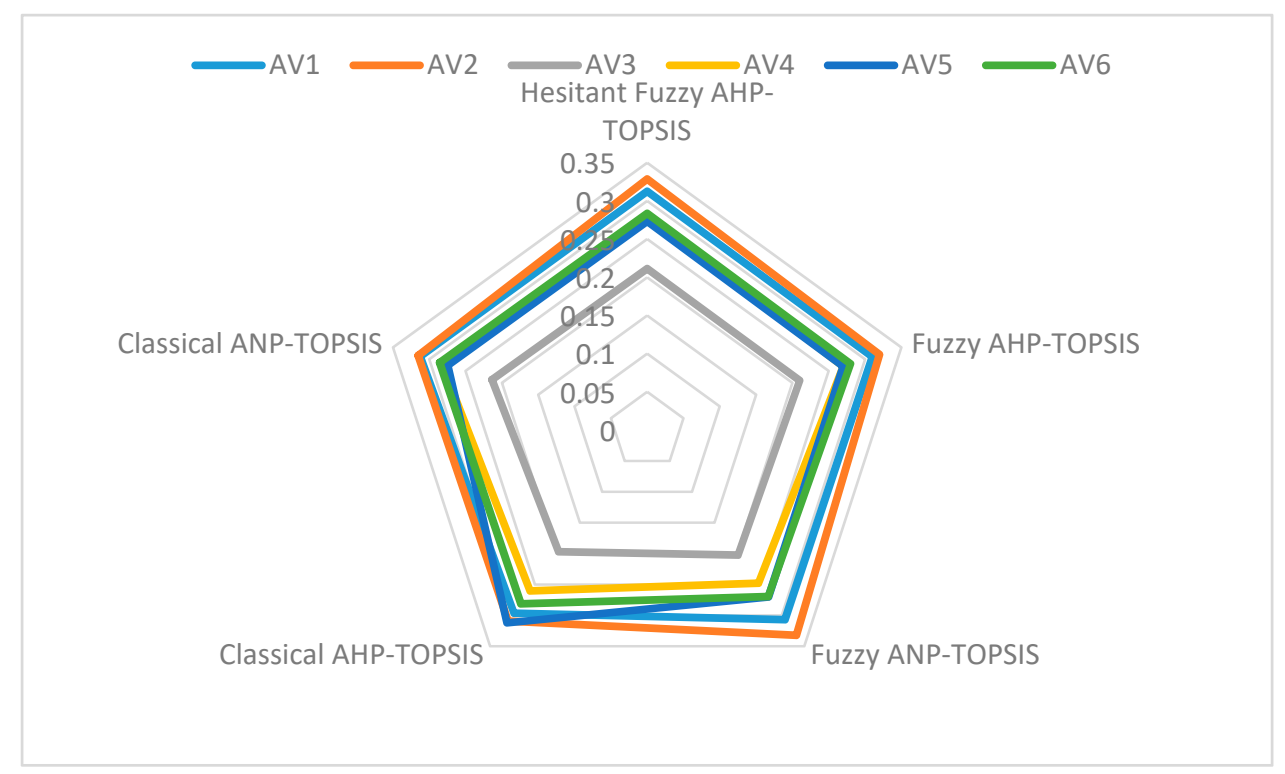

Figure 4. Graphical representation of comparison.

\section{Conclusions}

Providing a durable and user-friendly web application with low-cost maintenance is an ideal web application development process that every developer and expert expects. Low-cost maintenance and management web application process can only be accomplished by durability enhancement $[5,19,28]$. Managing and accessing the durability of web applications in the development phase is an important prerequisite towards realizing optimum durability. It is evidently shown by previous incidents that the main reason behind web application failures is the less focus on durability. The present study propositions that low-cost maintenance and long service life of web applications requires durability focused development procedure.

The contributions of this study can be capsuled as:

- Maintaining the durability of web applications gives cost-related enhancements and provides low-cost investment in web application management.

- The findings of the proposed work will facilitate the developers' task who can refer to the results and employ the stated methodology for enhancing the durability of web application instead of focusing on its application-level characteristics.

- The assessment section of this paper portrays that trustworthiness is the most important priority factor for durability enhancement in web applications. Therefore, it is automatically proven that focusing on trustworthiness can give high durability in web applications.

Durability enhancement of the web application development process demands greater and immediate focus of the practitioners. Estimating web application's durability in its development process was the core objective of the proposed study. For accomplishing the stated objective, we used the MCDM methodology to assess various design level characteristics of durability. Moreover, as a recommendation, the paper also emphasizes upon adopting durability management from the development phase of the web application for high longevity. The proposed methodology and processes were applied on the web applications of BBA University. The research also proposes a new idea of managing the durability of web applications through Hesitant-fuzzy-AHP based methodology. Different studies and surveys cite that nearly $75 \%$ of the cost is spent on web application management 
in businesses $[18,19,28]$. Thus, enhancement in the durability of web applications will give low-cost management of web applications and bring forth lucrative returns for the organizations. Yet another future endeavor in this research premise, as shown in the study, can be to enlist soft computing artificial intelligence for enhancing and evaluating web application's durability.

Author Contributions: Conceptualization, K.S. and F.A.A. and R.K.S.; methodology, F.A.A.; software, K.S., F.A.A. and R.K.S.; validation, R.K.S. and R.K.; formal analysis, F.A.A.; investigation, F.A.A.; resources, F.A.A.; data curation, K.S. and R.K.S.; writing—original draft preparation, K.S. and R.K.S.; writing—review and editing, F.A.A. and R.K.; visualization, K.S.; supervision, R.K.S.; project administration, F.A.A.; funding acquisition, F.A.A. All authors have read and agreed to the published version of the manuscript.

Funding: The project has been funded by King Abdul-Aziz City for Science and Technology (KACST), Kingdom of Saudi Arabia.

Acknowledgments: The work is funded by grant number 12-INF2970-10 from the National Science, Technology and Innovation Plan (MAARIFAH), the King Abdul-Aziz City for Science and Technology (KACST), Kingdom of Saudi Arabia. We thank the Science and Technology Unit at Um Al-Qura University for their continued logistics support.

Conflicts of Interest: The authors declare no conflict of interest.

\section{References}

1. Tekinerdogan, B.; Sozer, H.; Aksit, M. Software architecture reliability analysis using failure scenarios. J. Syst. Softw. 2008, 81, 558-575. [CrossRef]

2. FCW Workshop. Durable Cost Savings in Government IT. 2016. Available online: https://fcw.com/articles/ 2016/04/22/cost-savings-oped.aspx (accessed on 20 October 2018).

3. Thomas, B. Cisco Global Cloud Index 2015-2020. Available online: https://www.cisco.com/c/dam/m/ en_us/service-provider/ciscoknowledgenetwork/files/622_11_15-16-Cisco_GCI_CKN_2015-2020_AMER_ EMEAR_NOV2016.pdf (accessed on 10 August 2020).

4. Lambert, S. SaaS Industry Market Report: Key Global Trends \& Growth Forecasts. Finances Online. 2018. Available online: https://financesonline.com/2018-saas-industry-market-report-key-global-trends-growthforecasts/ (accessed on 4 September 2018).

5. Sommardahl, B. Durable Software. Awkward Coder Learning to Behave in Public 5-8. 2013. Available online: https://www.durable-north-america.com/service/duraprint-software.html (accessed on 24 August 2020).

6. Kumar, R.; Khan, A.I.; Abushark, Y.B.; Alam, M.M.; Agrawal, A.; Khan, R.A. A Knowledge Based Integrated System of Hesitant Fuzzy Set, AHP and TOPSIS for Evaluating Security-Durability of Web Applications. IEEE Access 2020, 8, 48870-48885. [CrossRef]

7. Chong, C.Y.; Lee, S.P.; Ling, T.C. Prioritizing and fulfilling quality attributes for virtual lab development through application of fuzzy analytic hierarchy process and software development guidelines. Malays. J. Comput. Sci. 2014, 27, 1-19.

8. Khan, S.A.; Alenezi, M.; Agrawal, A.; Kumar, R.; Khan, R.A. Evaluating Performance of Software Durability through an Integrated Fuzzy-Based Symmetrical Method of ANP and TOPSIS. Symmetry 2020, 12, 493. [CrossRef]

9. Agrawal, A.; Zarour, M.; Alenezi, M.; Kumar, R.; Khan, R.A. Security durability assessment through Fuzzy Analytic Hierarchy process. PeerJ Comput. Sci. 2019, 5, e2115. [CrossRef]

10. Cevik-Onar, S.; Oztaysi, B.; Kahraman, C. Strategic decision selection using hesitant fuzzy TOPSIS and interval type-2 fuzzy AHP: A case study. Int. J. Comput. Intell. Syst. 2014, 7, 1002-1021. [CrossRef]

11. Wang, C.N.; Thanh, N.V.; Su, C.C. The Study of a Multicriteria Decision Making Model for Wave Power Plant Location Selection in Vietnam. Processes 2019, 7, 650. [CrossRef]

12. Kahraman, C. (Ed.) Fuzzy Multi-Criteria Decision Making: Theory and Applications with Recent Developments; Springer Science \& Business Media: Berlin, Germany, 2008; Volume 16.

13. Roy, B.; Misra, S.K. An Integrated Fuzzy ANP and TOPSIS Methodology for Software Selection under MCDM Perspective. Int. J. Innov. Res. Comput. Commun. Eng. 2018, 6, 492-501.

14. Tavana, M.; Zandi, F.; Katehakis, M.N. A hybrid fuzzy group ANP-TOPSIS framework for assessment of e-government readiness from a CiRM perspective. Inf. Manag. 2013, 50, 383-397. [CrossRef]

15. Li, B.Z.; Bi, R. The Application of Fuzzy-ANP in Evaluation Index System of Computer Security. Key Eng. Mater. 2010, 439-440, 754-759. [CrossRef] 
16. Kumar, R.; Khan, S.A.; Agrawal, A.; Khan, R.A. Measuring the security attributes through fuzzy analytic hierarchy process: Durability perspective. ICIC Express Lett. 2018, 12, 615-620.

17. Hahn, W.J.; Seaman, S.L.; Bikel, R. Making decisions with multiple attributes: A case in sustainability planning. Graziadio Bus. Rev. 2012, 15, 365-381.

18. Cusick, J.J. Durable Ideas in Software Engineering: Concepts, Methods and Approaches from My Virtual Toolbox; Bentham Science Publishers: Sharjah, UAE, 2013; Available online: https://www.amazon.com/Durable-IdeasSoftware-Engineering-Approaches-ebook/dp/B00E7TCBEI (accessed on 16 August 2020).

19. Ensmenger, N. When good software goes bad: The surprising durability of an ephemeral technology. In Proceedings of the MICE Mistakes, Ignorance, Contingency and Error in Science and Technology, Munich, Germany, 2-4 October 2014; pp. 1-16.

20. Kelty, C.; Erickson, S. The Durability of Software; Meson Press: Lüneburg, Germany, 2015; Volume 1, pp. 1-13.

21. Torra, V.; Narukawa, Y. On hesitant fuzzy sets and decision. In Proceedings of the 2009 IEEE International Conference on Fuzzy Systems, Jeju Island, Korea, 20-24 August 2009; IEEE: Piscataway, NJ, USA, 2009; pp. 1378-1382.

22. Rodriguez, R.M.; Martinez, L.; Herrera, F. Hesitant fuzzy linguistic term sets for decision making. IEEE Trans. Fuzzy Syst. 2011, 20, 109-119. [CrossRef]

23. Rodriguez, R.M.; Martinez, L.; Torra, V.; Xu, Z.S.; Herrera, F. Hesitant fuzzy sets: State of the art and future directions. Int. J. Intell. Syst. 2014, 29, 495-524. [CrossRef]

24. Beg, I.; Rashid, T. Multi-criteria trapezoidal valued intuitionistic fuzzy decision making with Choquet integral based TOPSIS. Opsearch 2014, 51, 98-129. [CrossRef]

25. Xia, M.; Xu, Z. Hesitant fuzzy information aggregation in decision making. Int. J. Approx. Reason. 2011, 52, 395-407. [CrossRef]

26. Saaty, T.L. The Analytic Network Process. In Encyclopedia of Operations Research and Management Science; Springer: Berlin/Heidelberg, Germany, 2001. [CrossRef]

27. Hwang, C.L.; Lai, Y.J.; Liu, T.Y. A new approach for multiple objective decision making. Comput. Oper. Res. 1993, 20, 889-899. [CrossRef]

28. Feenstra, R.C.; Knittel, C.R. Re-assessing the U.S. quality adjustment to computer prices: The role of durability and changing software. In Working Paper Series-Department of Economics; NBER: Cambridge, MA, USA, 2004; pp. $2-50$.

Publisher's Note: MDPI stays neutral with regard to jurisdictional claims in published maps and institutional affiliations.

(C) 2020 by the authors. Licensee MDPI, Basel, Switzerland. This article is an open access article distributed under the terms and conditions of the Creative Commons Attribution (CC BY) license (http://creativecommons.org/licenses/by/4.0/). 